\title{
Assessment of the Metabolism of Different Strains of Bacillus megaterium
}

\author{
Carlos Alberto Galeano Suarez, Inti Doraci Cavalcanti Montano, Edson Romano Nucci, \\ Monica Rosas da Costa Iemma, Raquel de Lima Camargo Giordano and Roberto de \\ Campos Giordano* \\ Departamento de Engenharia Química; Universidade Federal de São Carlos; Via Washington Luiz, Km 235; \\ 13565-905; São Carlos - SP - Brasil
}

\begin{abstract}
Bacillus megaterium is a promising host for expression of heterologous proteins. This paper reports the nutrient consumption patterns and production of metabolites for three different strains of B. megaterium, ATCC 14945, QMB 1551 and PV 361, which is QMB 1551 with seven constitutive plasmids deleted. 14 h cultivations in agitated flasks were run, for two different media: A (LB plus $10 \mathrm{~g} / \mathrm{L}$ glucose) and B (medium A, with the yeast extract replaced by tryptone). Strains PV361 and QMB 1551 showed higher maximum specific growth rates in medium $B$, reaching $0.42 h^{-1}$ and $0.48 h^{-1}$ respectively. The main by-products of the glucose overflow mechanism were acetate and lactate, for all three strains, which had preferential amino acids for substrate: Ala, Asp, Glu, Ser. No production of alcohols was detected.
\end{abstract}

Key words: metabolic profile, Bacillus megaterium, culture media

\section{INTRODUCTION}

Bacillus megaterium offers advantages that make this gram-positive, aerobic, endospore-forming bacterium a promising candidate for the production and secretion of recombinant proteins. It uses a large variety of substrates, does not generate endotoxins, shows high secretion capacity (Vary 1994), absence of alkaline proteases (Rygus and Hillen, 1991), and stability of plasmids when compared with Bacillus subtilis (Meinhardt et al. 1989).

An example of industrial application of this vector is to intensify the expression of penicillin $G$ acylase (PGA) by the pac gene of Bacillus megaterium itself. $B$. megaterium has one advantage over $E$. coli for the production of this enzyme: the machinery for secreting the enzyme is present in the wild strains. Thus, cultivation of $E$. coli, which still is the major industrial production choice for PGA, has an economic drawback; the enzyme has to be extracted from its periplasmic space, consequently elevating production costs.

PGA is one of the most important enzymes used at an industrial scale and its extra-cellular production by Bacillus megaterium ATCC 14945 has been studied for several years by our group (Pinotti et al. 2000, 2007). It catalyzes the hydrolysis of penicillin $G$ (benzyl penicillin) to produce 6aminopenicillanic acid (6-APA), a key component for the synthesis of $\beta$-lactam antibiotics (Yang et al. 2006)

The endogenous production of PGA by Bacillus megaterium undergoes strong catabolic repression

*Author for correspondence: roberto@ufscar.br 
by glucose and glycerol, which are usually employed for cultivations aiming at high cell densities, since they are easily-assimilated carbon sources (Pinotti et al. 2007). Silva et al. (2006) suggest the use of an amino acid-free medium to overcome this problem, but with the drawback of decreasing the specific growth rates. Cloning $B$. megaterium pac gene in $B$. megaterium itself, while using a promoter (xylose) to control the expression, is an alternative presently being studied in our group, aiming at the over-expression of PGA. This would allow high cell density cultivations, using glucose as carbon source, with a consequent increase in the productivity of the process. It is expected that by increasing the number of cloned plasmids containing the pac gene in B.megaterium, the PGA expression level would increase as well. However, the size and number of the endogeneous plasmids in the microorganism may prevent the cloning of a high number of pac copies. Therefore, the deletion of the endogeneous plasmids from the wild strain is a promising strategy to enhance the xylose induced PGA expression. On the other hand, cultivation of $B$. megaterium at high densities poses some difficulties: high levels of glucose induce acidic aerobic fermentation (overflow mechanism), while depletion of the carbon source and/or accumulation of lactate and acetate induces sporulation (Galeano-Suárez 2010). Sporulation in Bacillus sp. is also a key factor to optimize bioreactor operation. For B. subtilis, Carvalho et al. (2010) report this phenomenon in aerobic cultivations after glucose depletion.

With this scope, it is important to assess the consumption patterns of substrates, of cell growth and of metabolite generation for this microorganism. Three different strains of $B$. megaterium were studied here, ATCC 14945, QMB 1551 and PV 361. The strain PV 361 is a QMB 1551 with all seven constitutive plasmids deleted. Therefore, this study will allow not only to identify common metabolic patterns between B.megaterium ATCC 14945, the strain used in our group, and QMB 1551, but also to correlate the deletion of the endogeneous plasmids with these patterns. The microorganisms were grown in flasks in two media: a standard medium (Lysogeny Broth, LB), here called medium $\mathrm{A}$ and a modification of this medium, replacing tryptone by yeast extract, medium B. Yeast extract, obtained by autolysis and debris separation of baker's or brewer's yeast, is rich in nitrogen. Its typical composition is $8-12 \%$ of total nitrogen, and from this $3.0-5.2 \%$ is amino nitrogen. It has $4-13 \%$ of total carbohydrate, $13 \%$ of ash, vitamins and other growth stimulating compounds. The main elements found in yeast extract ashes are $\mathrm{Mg}, \mathrm{Fe}$, $\mathrm{Zn}$ and $\mathrm{Cu}$, with $1270,150,74$ and $71 \mu \mathrm{g} / \mathrm{g}_{\text {dry w }}$, respectively (Grant and Pramer 1962).

Tryptone is protein hydrolyzed by trypsyn. Thus, with respect to $\mathrm{N}$, it is a rich source of amino-acid nitrogen. This study will contribute to a better understanding of the role of these two different nitrogen sources for B. megaterium growth.

\section{MATERIALS AND METHODS}

\section{Material and microorganism}

Yeast extract and tryptone (hydrolyzed casein) were purchased from Acumedia. Glucose, from Vetec. All other reagents were of analytical grade from several commercial brands. Bacillus megaterium ATCC 14945 was kindly donated by Tropical Foundation, Campinas/SP, Brazil. B. megaterium PV 361 and QMB 1551 were graciously donated by Prof. Patricia S. Vary, Northern Illinois University. Strain PV 361 is a variant of QMB 1551, where the genes of its seven constitutive megaplasmids were deleted.

\section{Inoculum Preparation (Germination)}

$5 \mathrm{~mL}$ of spores of $B$. megaterium stored with glycerol in cryovials at $-70{ }^{\circ} \mathrm{C}$ were transferred to $500 \mathrm{~mL}$ Erlenmeyer flasks containing $45 \mathrm{~mL}$ of growth medium. Medium "A" contained: LB medium (Bertani, 1951) with yeast extract $(5 \mathrm{~g} / \mathrm{L})$, tryptone $(10 \mathrm{~g} / \mathrm{L})$ and sodium chloride $(10 \mathrm{~g} / \mathrm{L})$, plus glucose $(10 \mathrm{~g} / \mathrm{L})$. Medium "B" had tryptone replaced by the same concentration of yeast extract $(15 \mathrm{~g} / \mathrm{L}$ in total). The inoculum was grown at $30{ }^{\circ} \mathrm{C}, 250 \mathrm{rpm}$ for $12 \mathrm{~h}$.

\section{Cultivation in flasks}

$5 \mathrm{~mL}$ of inoculum were transferred to $500 \mathrm{~mL}$ Erlenmeyer flasks containing $45 \mathrm{~mL}$ of medium and kept in a shaker (Marconi, Brazil) at $30{ }^{\circ} \mathrm{C}$, initial $\mathrm{pH} 7.5,250 \mathrm{rpm}$ for $12 \mathrm{~h}$. The $\mathrm{pH}$ at the end of the cultivations was 6.5. Samples were collected every $2 \mathrm{~h}$, centrifuged for $20 \mathrm{~min}$ at $10,600 \mathrm{~g}$ and at $4{ }^{\circ} \mathrm{C}$ (Eppendorf centrifuge, model 54030). The supernatant was used to monitor the consumption of nutrients and the production of metabolites. 


\section{Cell Concentration}

Dry cell mass was determined by centrifuging 2 $\mathrm{ml}$ of medium in a refrigerated centrifuge, followed by drying at $60{ }^{\circ} \mathrm{C}$ for $24 \mathrm{~h}$. Cell concentrations were also monitored by measuring the optical density (OD) at $600 \mathrm{~nm}$ (Pharmacia spectrophotometer ULTROSPEC 2000). The correlation between dry cell weight (DCW) and optical density $\left(\mathrm{DO}_{600 \mathrm{~nm}}\right)$ was $\mathrm{DCW}(\mathrm{g} / \mathrm{L})=$ $0.420 \times \mathrm{DO}_{600 \mathrm{~nm}}+0.164$.

\section{Analysis}

Carbohydrates and organic acids were measured by high performance liquid chromatography (Waters) using an ion exchange column Aminex HPX-87H, Bio-Rad and $5 \mathrm{mM}$ sulfuric acid solution as mobile phase $(0.6 \mathrm{~mL} / \mathrm{min})$. The temperature for separating the components was 50 ${ }^{\circ} \mathrm{C}$. Detection of organic acids occurred at $210 \mathrm{~nm}$. Glucose and alcohols were measured in a refraction index detector.

For amino acids, a Pico-tag system was used: reverse-phase chromatography with pre-column derivatization of the samples. The derivatization reactant consisted of a solution of ethanol, triethylamine, phenyl isothiocyanate and water in the ratio $7: 1: 1: 1(\mathrm{v} / \mathrm{v})$. For separation, two mobile phases were used, sodium acetate trihydrate $\mathrm{pH}$ 6.4 and acetonitrile $60 \% \mathrm{v} / \mathrm{v}$, at a flow rate of 1.0 $\mathrm{mL} / \mathrm{min}$.

\section{RESULTS}

Figures 1, 2 and 3 illustrate the profiles of cell concentration, glucose concentration and organic acids produced during cultivations of $B$. megaterium ATCC 14945 (ATCC), PV 361 (PV) and QMB $1551(\mathrm{QM})$, respectively, for the two media tested. No detectable amounts of alcohols were present. From these data, it can be seen that $\mathrm{PV}$ and QM growing in medium B presented a higher maximum specific growth rate, $\mu_{\max } \mathrm{B}=042$ $\mathrm{h}^{-1}$ and $0.48 \mathrm{~h}^{-1}$ respectively.

Figure 4 shows the amino acids consumption by the ATCC strain growing in media A and B. It is apparent that the presence of tryptone, composed of oligopeptides obtained after the enzymatic hydrolysis of casein by trypsin, inhibits the consumption of free amino acids present in the yeast extract. Thus, amino acid consumption rates are higher for medium $B$.

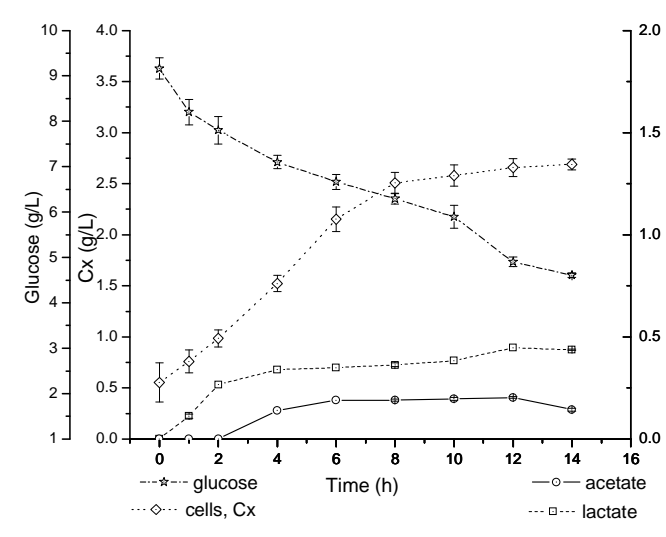

A

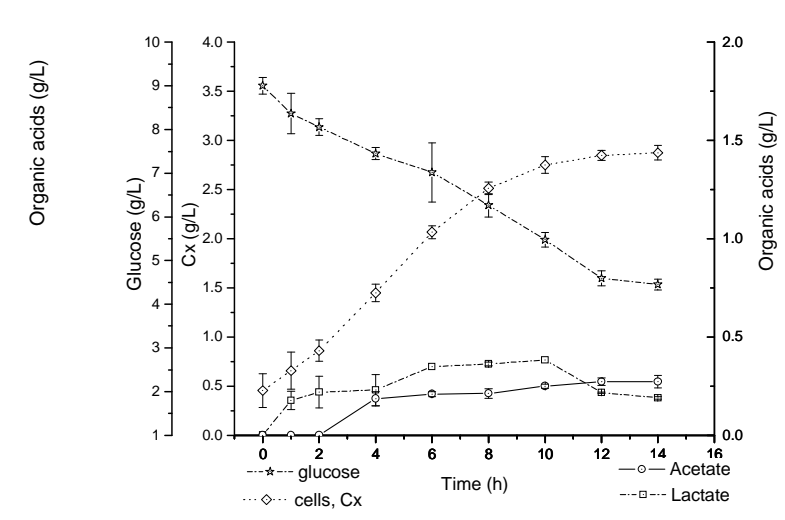

B

Figure 1 - Evolution of cell concentration, glucose consumption and production of organic acids during cultivation of Bacillus megaterium ATCC using: (A) medium A (glucose+LB), (B) medium $\mathrm{B}$ (glucose, $\mathrm{NaCl}$ and yeast extract). Error bars: standard deviation of triplicates. 


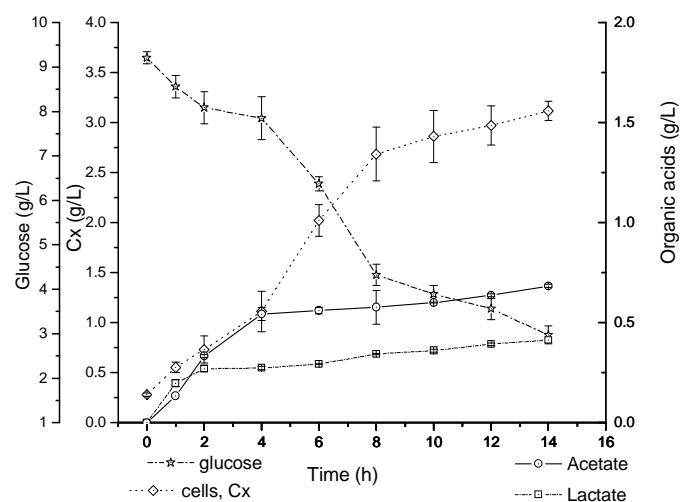

A

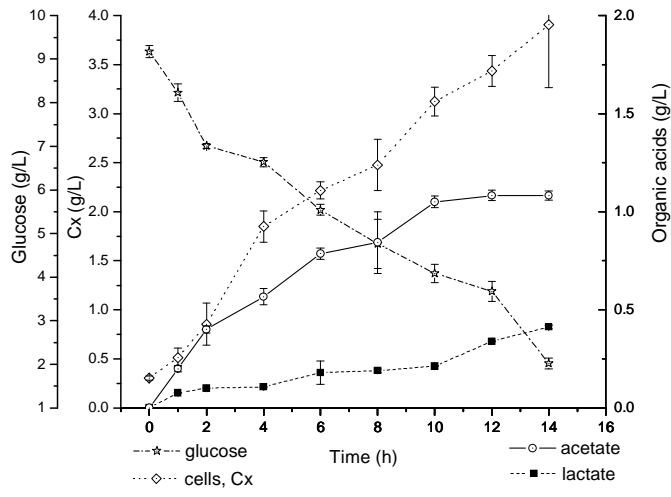

B

Figure 2 - Evolution of cell concentration, glucose consumption and organic acids during cultivation of Bacillus megaterium PV using: (A) medium A (glucose, $\mathrm{NaCl}$, yeast extract and tryptone), (B) medium $\mathrm{B}$ (glucose, $\mathrm{NaCl}$ and extract yeast). Error bar: standard deviation of triplicates.

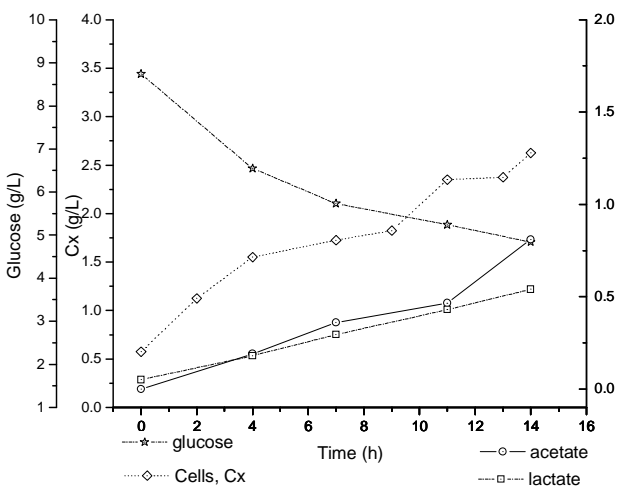

A

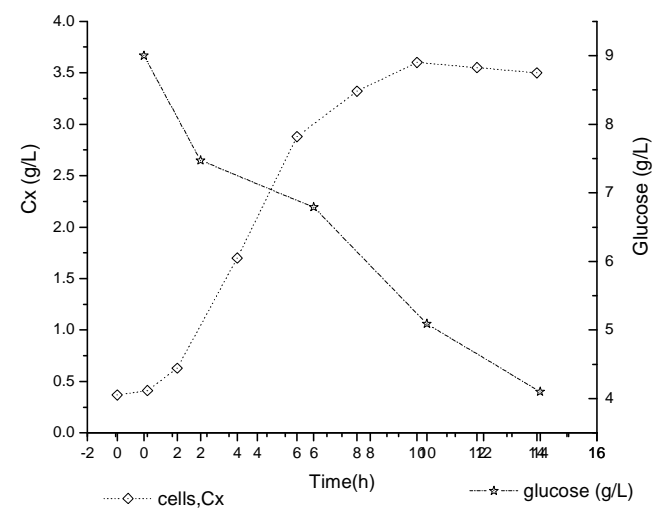

B

Figure 3 - Evolution of cell concentration, glucose consumption and organic acids during cultivation of Bacillus megaterium QM using: (A) medium A (glucose, $\mathrm{NaCl}$, yeast extract and tryptone). (B) medium $\mathrm{B}$ (glucose, $\mathrm{NaCl}$ and extract yeast).

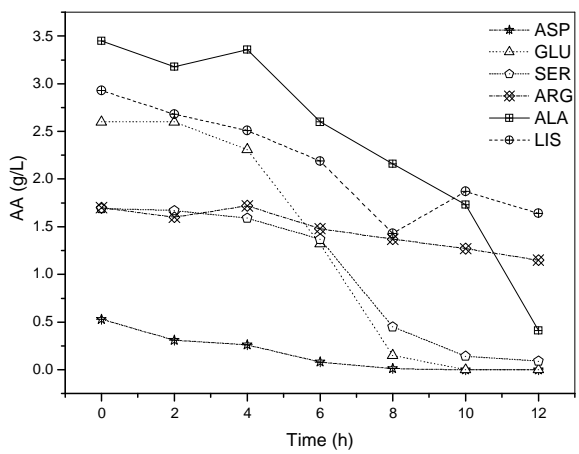

A

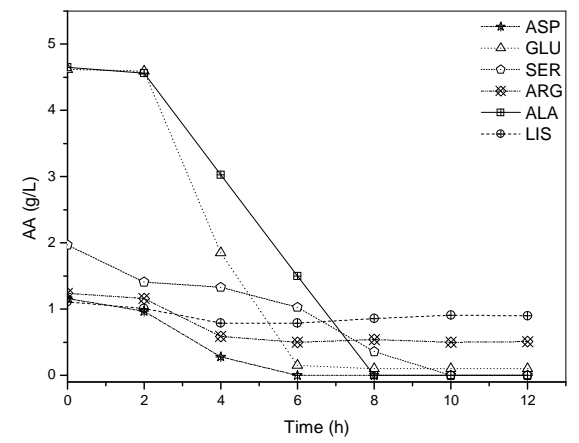

B

Figure 4 - Amino acids preferentially consumed by Bacillus megaterium ATCC 14945 using: (a) medium A; (b) medium B. 
Table 1 - Maximum concentrations of cells $(\mathrm{Cx})$, acetic acid and lactic acid, maximum specific growth rates $\left(\mu_{\max }\right)$ and cell/glucose yields $\left(\mathrm{Y}_{\mathrm{x} / \mathrm{s}}\right)$ in cultures of different strains of $B$. megaterium in shake flasks, in medium A (LB medium with $10 \mathrm{~g} / \mathrm{L}$ glucose) and medium B (replacement of tryptone by yeast extract), $30{ }^{\circ} \mathrm{C}, \mathrm{pH} 7.5$. Cell concentration measured after $14 \mathrm{~h}$ of cultivation. Standard deviations estimated from independent triplicates. Growth parameters estimated in the exponential phase.

\begin{tabular}{|c|c|c|c|c|c|c|}
\hline Microorganism & $\begin{array}{c}\text { Culture } \\
\text { medium }\end{array}$ & $\begin{array}{c}\mathbf{C x} x_{\max } \\
\left(g_{d r y ~ c e l l} / \mathbf{L}\right) \\
\end{array}$ & $\begin{array}{c}\text { Max. Acetate } \\
(\mathrm{g} / \mathrm{L})\end{array}$ & $\begin{array}{c}\text { Max. Lactate } \\
(\mathrm{g} / \mathrm{L})\end{array}$ & $\begin{array}{l}\mu_{\max } \\
\left(\mathbf{h}^{-1}\right)\end{array}$ & $\mathbf{Y}_{\mathrm{x} / \mathrm{s}}$ \\
\hline $\begin{array}{l}\text { B. megaterium } \\
\text { ATCC } 14945\end{array}$ & A & $2.69 \pm 2.2 \times 10^{-2}$ & $0.20 \pm 4.0 \times 10^{-3}$ & $0.44 \pm 1.0 \times 10^{-4}$ & $\mathbf{0 . 2 3} \pm 1.1 \times 10^{-2}$ & $0.49 \pm 8.3 \times 10^{-2}$ \\
\hline $\begin{array}{l}\text { B. megaterium } \\
\text { ATCC } 14945\end{array}$ & B & $\mathbf{2 . 8 8} \pm 7.4 \times 10^{-2}$ & $0.27 \pm 3.2 \times 10^{-2}$ & $\mathbf{0 . 3 8} \pm 1.0 \times 10^{-4}$ & $0.26 \pm 2.0 \times 10^{-3}$ & $\mathbf{0 . 5 3} \pm 9.0 \times 10^{-2}$ \\
\hline $\begin{array}{c}\text { B. megaterium } \\
\text { PV }\end{array}$ & A & $3.11 \pm 9.4 \times 10^{-2}$ & $0.68 \pm 8.0 \times 10^{-3}$ & $\mathbf{0 . 4 1} \pm 1.0 \times 10^{-4}$ & $\mathbf{0 . 2 3} \pm 1.7 \times 10^{-2}$ & $\mathbf{0 . 4 6} \pm 4.2 \times 10^{-2}$ \\
\hline $\begin{array}{c}\text { B. megaterium } \\
\text { PV }\end{array}$ & B & $3.91 \pm 6.4 \times 10^{-1}$ & $\mathbf{1 . 0 8} \pm 2.3 \times 10^{-2}$ & $\mathbf{0 . 4 1} \pm 1.0 \times 10^{-2}$ & $0.42 \pm 3.0 \times 10^{-2}$ & $\mathbf{0 . 5 0} \pm 9.1 \times 10^{-2}$ \\
\hline $\begin{array}{c}\text { B. megaterium } \\
\mathrm{QM}^{* *}\end{array}$ & A & $\begin{array}{l}\mathbf{2 . 4 5} * * \\
\mathbf{2 . 8 0} * * \\
\end{array}$ & $\begin{array}{l}0.83 * * \\
0.79 * *\end{array}$ & $\begin{array}{l}0.48 * * \\
0.60 * *\end{array}$ & $\begin{array}{l}0.28 * * \\
0.22 * * \\
\end{array}$ & $\begin{array}{l}0.51 * * \\
0.54 * *\end{array}$ \\
\hline $\begin{array}{c}\text { B. megaterium } \\
\text { QM }\end{array}$ & B & $\mathbf{3 . 6 0} \pm 5.3 \times 10^{-1}$ & n.a & n.a. & $0.48 \pm 2.1 \times 10^{-2}$ & $0.64 \pm 2.0 \times 10^{-1}$ \\
\hline
\end{tabular}

** Experiments in duplicate.

\section{DISCUSSION}

Figure 1 indicates that B. megaterium ATCC consumed approximately the same amount of glucose $(4.5 \mathrm{~g} / \mathrm{L})$ for both media. The profiles for the two media, $A$ and $B$, are very similar, indicating that tryptone did not significantly affect the metabolism of the microorganism. Lactate and acetate were the main metabolic side products (in this order). The production of lactate starts right at the beginning of the assay, followed by acetate. It seems to be a common trend in the organic acids curves to show a maximum concentration, indicating that these metabolites are used as carbon source when glucose approaches depletion. This behavior is also typical for E. coli: overflow of glucose (Crabtree effect) for high substrate concentrations, followed by the consumption of the organic acids (non-preferential substrates) when the sugar concentrations are low. The same behavior is apparent here, for B. megaterium. Another important observation is that no aerobic alcoholic fermentation route was noticed for this microorganism: all overflow of glucose is directed to acidic fermentation pathways.

Figure 2 shows the results for the PV strain. In this case, the cell growth rate was higher for medium B. The plasmid-deleted strain seems to show a marked preference for higher concentrations of yeast extract (medium B). Although medium B has a lower concentration of the nitrogen source, the other growth factors present in the yeast extract, whose concentration was higher in medium B, were important for the PV strain. The production of acetate, in this case, is higher than that of lactate, and the glucose threshold where the organic acids begin to be consumed is lower than for the ATCC strain. This behavior is presently being confirmed in fed-batch bioreactor cultivations (data not shown). Figure 3 shows that the behavior of the QM strain is similar to the PV one. It appears that the QM strain, regardless the presence or absence of the endogeneous plasmids, grows better in medium $\mathrm{B}$, without tryptone.

Table 1 shows cell concentrations after $14 \mathrm{~h}$, maximum concentrations of acetic acid and lactic acid, and conversion factors of glucose into cells for the three microorganisms. These values were obtained after three independent experiments for B. megaterium ATCC 14945 and B. megaterium PV and two independent experiments for $B$. megaterium QM. An estimate of the maximum specific growth rate for each case, taken after fitting the logarithm of $\mathrm{Cx}$ versus time in the linear region of the monolog graph, is also presented.

The results shown in Table 1 indicate that the three microorganisms presented similar $\mu_{\max }$ values for medium A, therefore similar metabolic patterns. On the other hand, for medium $\mathrm{B}$, where the concentration of growth factors present in the 
yeast extract is higher than in medium $\mathrm{A}, \mu_{\max }$ values for strain $\mathrm{QM}$ and its correspondent plasmid-deleted version, $\mathrm{PV}$, are approximately the double of the ATCC $\mu_{\max }$. Therefore, it seems that $\mathrm{QM}$ is dependent on some growth factors present in the yeast extract. The consumption of amino acids in the medium is another important point to assess the balance of nitrogen for $B$. megaterium. Figure 4 shows the amino acids consumption by the ATCC strain growing in media A and B. It is apparent that the presence of tryptone, composed of oligopeptides obtained after the enzymatic hydrolysis of casein by trypsin, inhibits the consumption of free amino acids present in the yeast extract. Thus, the amino acid consumption rates are higher for medium B. It can be observed that glutamic acid, aspartic acid, alanine and serine are preferentially consumed. Of all, the two acids are the most quickly consumed. Other amino acids have a much lower consumption rate (data not shown). Similar trends were observed for the three strains.

In order to select the best strain of Bacillus megaterium to reach high cell densities during fedbatch cultivations in bioreactors after the intensification of the PGA gene in this bacterium, the metabolic patterns of three strains of the microorganism were assessed using two different media. The results indicated that the strain PV 361, a QMB 1551 with its seven endogeneous plasmids deleted, presented metabolic patterns similar to QMB 1551 (with plasmids). Therefore, if the plasmids deletion is needed to improve PGA expression, it will not affect cell growth. When comparing the metabolism of the three strains, the results indicated that, although similar behaviors were found when medium A was used, the growth of QMB 1551 and PV 361 strains is strongly influenced by some growth factor present in the yeast extract. Overflow of glucose resulted in acid fermentation for all strains, producing mostly lactate and acetate which are further consumed as non-preferential substrates when glucose is near depletion. Glutamic acid, aspartic acid, alanine and serine are preferentially consumed by all strains.

\section{ACKNOWLEDGMENTS}

The authors wish to thank FAPESP, CNPq and CAPES for financial support and Prof. Patricia Vary for kindly providing QMB 1551 and PV 361.

\section{REFERENCES}

Bertani G. Studies on lysogenesis. I. The mode of phage liberation by lysogenic Escherichia coli. J Bacteriol. 1951; 62: 293-300.

Carvalho ALU, Oliveira FHPR, Mariano RLR, Gouveia ER, Souto-Maior AM. Growth, sporulation and production of bioactive compounds by Bacillus subtilis R14. Braz Arch Biol Technol. 2010; 53: 643652.

Galeano-Suarez, CA. Optimization of the cultivation of recombinant Bacillus megaterium in fed-batch mode. [MSc Dissertation]. São Carlos, Brasil: University Federal of São Carlos; 2010.

Grant CL, Pramer D. Minor element composition of yeast extract. J. Bacteriology. 1962; 84: 869-870.

Meinhardt F, Stahl U, Ebelinget W. Highly efficient expression of homologous and heterologous genes in Bacillus megaterium. Appl Microbiol Biotechnol. 1989; 30: 343-350.

Pinotti LM, Silva AFS, Silva RG, Giordano RLC. Study of Different Media for production of Penicillin G Acylase from Bacillus megaterium ATCC 14945. Appl Biochem Biotech. 2000; 84-86: 655-663.

Pinotti LM, Souza VR, Giordano RC, Giordano RLC. The penicillin $\mathrm{G}$ acylase production by $b$. megaterium is amino acid consumption dependent. Biotech Bioeng. 2007; 97: 346-353.

Rajendhran J, Gunasekaran P. Recent Biotechnological Interventions for Developing Improved Penicillin G Acylases. J Bioscience Bioeng. 2004; 97: 1-13.

Rygus T, Hillen W. Inducible high-level expression of heterologous genes in Bacillus megaterium using regulatory elements of the xylose-utilization operon. Appl Microbiol Biotechnol. 1991; 35: 594-599.

Silva RG, Souza VR, Nucci ER, Pinotti LM, Cruz AJG, Giordano RC, Giordano RLC. Using a medium of free amino acids to produce penicillin $\mathrm{G}$ acylase in fed-batch cultivations of Bacillus megaterium ATCC 14945. Braz J Chem Eng. 2006; 23: 37-43.

Souza VR, Silva ACG, Pinotti LM, Araújo HSS, Giordano RLC. Characterization of the Penicillin G Acylase from Bacillus megaterium ATCC 14945. Braz Arch Biol Technol. 2005; 48: 105-111.

Vary PS. Prime time for Bacillus megaterium. Microbiology. 1994; 140: 1001-1013.

Yang Y, Biedendieck R, Wang W, Gamer M, Malten M, Jahn D, et al. High Yield Recombinant Penicillin $\mathrm{G}$ Amidase Production and Export into the Growth Medium Using Bacillus megaterium. Microbial Cell Factories. 2006; 5: 24-42. 